\title{
Fish Hobbyists' Willingness to Donate for Wild Fighting Fish (Betta livida) Conservation in Klang Valley
}

\author{
Muhammad Fairus Abd Rahman ${ }^{1}$ and Nitanan Koshy Matthew ${ }^{1,2, * \text { (D) }}$ \\ 1 Department of Environment, Faculty of Forestry and Environment, Universiti Putra Malaysia, \\ Serdang 43400, Malaysia; abdr.fairus@gmail.com \\ 2 Institute of Tropical Agriculture and Food Security (ITAFoS), Universiti Putra Malaysia, \\ Serdang 43400, Malaysia \\ * Correspondence: nitanankoshy@upm.edu.my
}

Citation: Abd Rahman, M.F.; Matthew, N.K. Fish Hobbyists' Willingness to Donate for Wild Fighting Fish (Betta livida) Conservation in Klang Valley. Sustainability 2021, 13, 10754 https://doi.org/10.3390/ su131910754

Academic Editor: Vasilios Liordos

Received: 31 July 2021

Accepted: 2 September 2021

Published: 28 September 2021

Publisher's Note: MDPI stays neutral with regard to jurisdictional claims in published maps and institutional affiliations.

Copyright: (c) 2021 by the authors. Licensee MDPI, Basel, Switzerland. This article is an open access article distributed under the terms and conditions of the Creative Commons Attribution (CC BY) license (https:// creativecommons.org/licenses/by/ $4.0 /)$.

\begin{abstract}
Betta livida is an endangered endemic species of wild fighting fish affected by habitat degradation and exploitation. Despite this concern, the literature on the conservation of wild betta is negligible. Conservation is a non-use value, whereas the species itself is a use-value because they are sought after in the ornamental fish trade business. Therefore, the contingent valuation method (CVM) was applied in this study to establish the monetary value for species conservation by determining hobbyists' willingness to donate (WTD) for conservation. Fish hobbyists are the most prominent backbone of the industry and are the most acquainted with the targeted species. Hence, hobbyists' knowledge, perceptions and attitude towards species conservation have also been explored and weighed against the WTD. Purposive sampling was employed with a total of 150 respondents in Klang Valley. The findings show that the WTD was influenced by double-bound CVM, age (AGE) and hobbyists who owned the species (OWNB). In contrast, knowledge, perceptions and attitudes were not significant. Using probit regression analysis, hobbyists' WTD for species conservation was MYR 9.04 annually. The survey also revealed concern for species that are wild-caught by hobbyists. Hence, the results of this study offer preliminary insights into the WTD for wild betta and local freshwater fish conservation in Malaysia.
\end{abstract}

Keywords: attitude; contingent valuation method; knowledge; perception; wild betta; willingness to donate

\section{Introduction}

Fighting fish (betta) have always been a popular preference for ornamental fish due to their vivid colour schemes, minimal set-up requirement and the unique showcase of the male betta displaying dominance by flaring their operculum and finnage when threatened. However, the most common betta is a captive crossbreed with particular traits of the Betta splenden, which are common and not under threat of endangerment. Wild betta fish are found in some endemic regions throughout Malaysia, Indonesia and Thailand. Tan and $\mathrm{Ng}$ (2005) [1] described numerous wild betta species found in Malaysia, including B. coccina, $B$. persephone and B. livida, the latter of which are the focus of this study (see Table 1).

Tan and $\mathrm{Ng}$ [1] described adult B. livida as having small, unique bodies (the standard length is less than $40 \mathrm{~mm}$ ), with a uniform deep red (maroon) body colour. They have midlateral bodies and both genders have an iridescent green blotch that often fades throughout adulthood. They have a parallel vertical iridescent gold bar on the operculum and a falcate pelvic fin with an iridescent green tip (Figure 1). The species may also be mistaken for another species, $B$. coccina. They are almost identical, except that the tip of the pelvic fin of $B$. coccina is black and they are found in different geographic areas. This classical look of wild betta and their rareness has made this species the most sought after in the ornamental fish trade. A pair might cost more than MYR 100 from private sellers and collectors. 
Table 1. Taxonomy of B. livida.

\begin{tabular}{ccccccc}
\hline Kingdom & Phylum & Class & Order & Family & Genus & Species \\
\hline Animalia & Chordata & Actinopterygii & Perciformes & Osphronemidae & Betta & livida \\
\hline Source: Ng and Kotellat (1992).
\end{tabular}

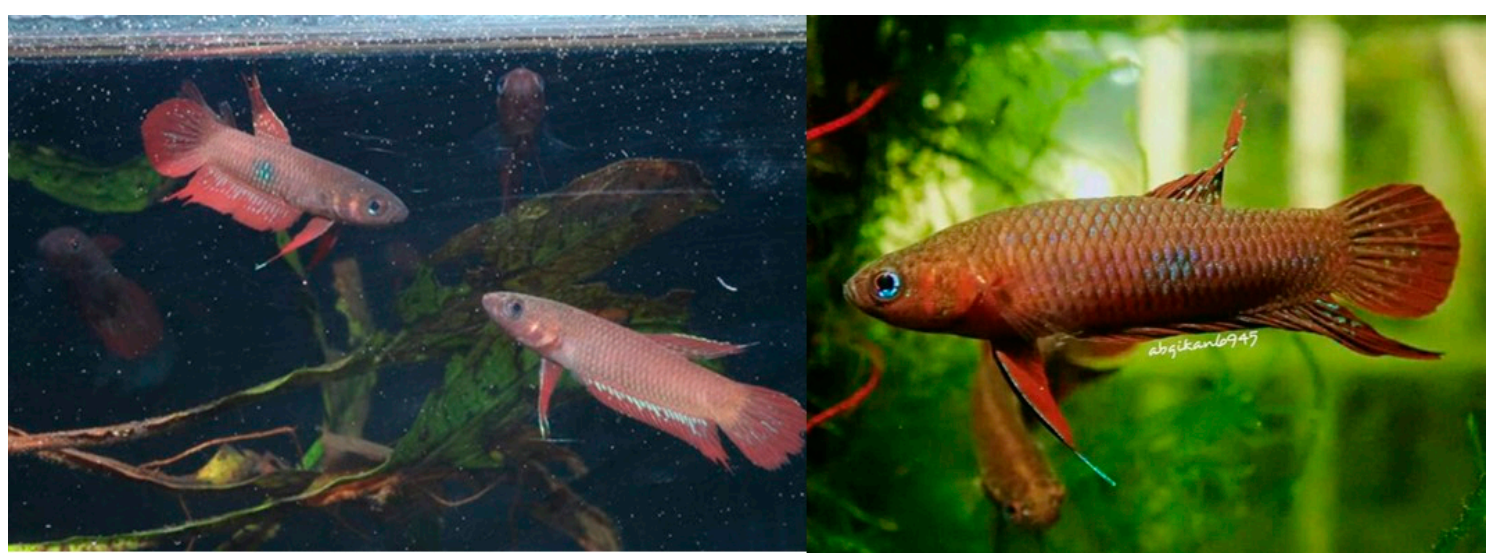

Figure 1. Photos of Betta livida (Photo credit: Muhammad Ilham Norhakim).

Research on the conservation of wild betta is still inadequate and requires further study. Keat-Chuan et al. [2] noted that the challenges in freshwater fish conservation were due to a lack of interest, funding and problems with unresolved taxonomic classification. The only established conservation research of wild betta was for B. persephone, a critically endangered and endemic species found in Johor [3]. Moreover, economic valuation for the conservation of local freshwater fish species in Malaysia has yet to be established. Eliciting monetary value would indicate how much the public is willing to pay (WTP) to protect ornamental, native fish and eventually urge authorities to act to conserve the species.

Developments in peat swamp forest areas have been detrimental to the environment; most ecosystems have been destroyed, resulting in the depletion of flora and fauna biodiversity. Betta livida is an example of an endemic species of the peat swamp forest in Selangor, which is in the Klang Valley (KV) area, a hub for rapid modern development. The recent issuance of a local state government proposing the degazetting of the North Kuala Langat Reserve Forest, which is home to B. livida, became a testament to a lack of conservation mindedness. Giam et al. [4] projected the extinction of B. livida and other swamp fish species by 2050 if environmental management and policies fail to protect their ecosystem. B. livida has also been classified as an endangered (EN) species in the Red List's International Union of Conservation of Nature (IUCN) [5]. Overexploitation in the ornamental fish trade will further endanger their status [2,6]. $\mathrm{Ng}$ [6] raised concern that the wild betta was excessively caught in wild habitats. Establishing the conservation of the species with a monetary value would provide critical information and enable the initiation of conservation and sustainable development with sound environmental management and policy formulation. Afterall, it would be a loss to Malaysia's biodiversity heritage if this native and endemic species only existed in history books.

Hobbyists are the primary consumers for this industry and key stakeholders in conservation. Therefore, it would be interesting to probe their response to the WTP for conservation of these and other endemic species. Hobbyists would contribute to species conservation via donation. Haefele et al. [7] noted that the use of taxes as elicitation might not appeal to the public due to tax burdens and scepticism about how the money would be used for species conservation. Willingness to pay (WTP) typically dictates that the fund be allocated to specific conservation funds or facilities. As no specific trust fund has been established for this species, a hypothetical trust fund was established. This trust aims to develop conservation efforts that encourage breeding and awareness programs 
and habitat gazetting for the B. livida species. Therefore, employing willingness to donate (WTD) instead of WTP throughout this study was more fitting.

The contingent valuation method (CVM) has been widely used in environmental studies as an economic tool. Environmentalists prefer it for its compatibilities with appraising the value and non-value environmental commodities [8,9]. For example, Greece's public WTP mean for edible sea urchins (Paracentrotus lividus) was EUR 56, which greatly influenced the perception of the species [10]. The perception revolves primarily around who is responsible for conserving the species, which falls to the government. In Sri Lanka, the reputation of Asian elephants (Elephas maximus) as agricultural pests was evaluated [11]. However, the public, especially those residing in urban areas, still favoured species conservation with a WTP per month of LKR 110.16 for five years, which could compensate for the farmers' losses in rural areas. In contrast, Asmamaw et al. [12] identified that the WTP for Labeobarbus fish in Lake Tana using labour days was 48.48 per household, which is equivalent to USD 4,422,792.4 per year. The WTP was significantly influenced by the respondents' age, sex and economic activities (i.e., fishery). This study found that species-level valuation focused on iconic species or species with a socio-economic effect. Because wild B. livida act as value and non-value commodities, CVM is an appropriate economic tool for evaluating the conservation of the species in monetary value.

Numerous economic valuations for Malaysia's environmental commodities revolve around WTP valuation for eco-tourism, such as reserved forests and recreational nature parks. For example, Shahwahid et al. [13] conducted a study on the perception of wild elephants in Pahang. They found a WTP mean of MYR 5.86 and a median of MYR 5.00 per person for species conservation. The amount implied the results, the age gap between the respondents and the older generation's enthusiasm for preserving biodiversity heritage for subsequent generations. In Semporna, Sabah, attention was centred on the total environmental value (TEV) of marine turtle conservation [14]. The estimated TEV utilising the CVM was USD 23 million per year from tourists and locals, indicating that the non-use value of the species surpassed the consumption use-value.

On the other hand, Vianna et al. [15] assessed shark-diving tourism as a funding mechanism for shark conservation, with a WTP mean of MYR 35.73 from tourists and guides. Marine Park authorities also generated approximately USD 2 million annually for environmental management and enforcement. These are significant indicators demonstrating the importance of non-use environmental commodities supporting society and ensuring that anthropocentric characteristics heavily influence WTP. At the same time, other factors, such as biocentrism, aesthetics and existence, are valued less.

Therefore, this study acts as preliminary research for the WTP for conserving wild betta and native freshwater fish in Malaysia. To better comprehend the matter, the study probed hobbyists' knowledge regarding the species and measured their perceptions and attitudes towards species conservation. Lastly, the estimation of the WTD for the species conservation was determined using double-bound CVM.

The results of this study aid in discussing and addressing the relevance of using WTD for B. livida wild fighting fish conservation among hobbyists in Klang Valley with possible inheriting factors, as follows:

Hypothesis $\mathbf{1}$ (H1). The mean WTD per hobbyist's income (INC) for species conservation is statically greater than 0 .

$$
\left(\mathrm{H}_{01}: \mathrm{WTP}_{\mathrm{INC}}>0, \mathrm{H}_{\mathrm{A} 1}: \mathrm{WTP}_{\mathrm{INC}}<0\right)
$$

Hypothesis 2 (H2). The mean WTD per hobbyist's perception towards the conservation of the species (PERC) is statistically greater than 0.

$$
\left(\mathrm{H}_{02}: \mathrm{WTP}_{\mathrm{PERC}}>0, \mathrm{H}_{\mathrm{A} 2}: \mathrm{WTP}_{\mathrm{PERC}}<0\right)
$$


Hypothesis 3 (H3). The mean WTD per hobbyist's attitude towards the conservation of the species (ATT) is statistically greater than 0.

$$
\left(\mathrm{H}_{03}: \mathrm{WTP}_{\text {ATT }}>0, \mathrm{H}_{\mathrm{A} 4}: \mathrm{WTP}_{\mathrm{ATT}}<0\right) .
$$

\section{Materials and Methods}

\subsection{Study Area, Sampling and Target Population}

Klang Valley (KV), with an unknown hobbyist population, was selected to be a study area based on the endemic distribution of B. livida [5]. KV, which comprises several state districts and federations, is the central hub for modernisation, transportation and industry. Although the description of KV differs in literature, eight (8) districts were selected as study areas. Figure 2 shows the geo-referencing map of B. livida distribution coupled with the study area's scope border. 'Resident' refers to the original distribution of the species within the established habitat, while 'extent' indicates species reported outside the habitat area due to the floodplain.

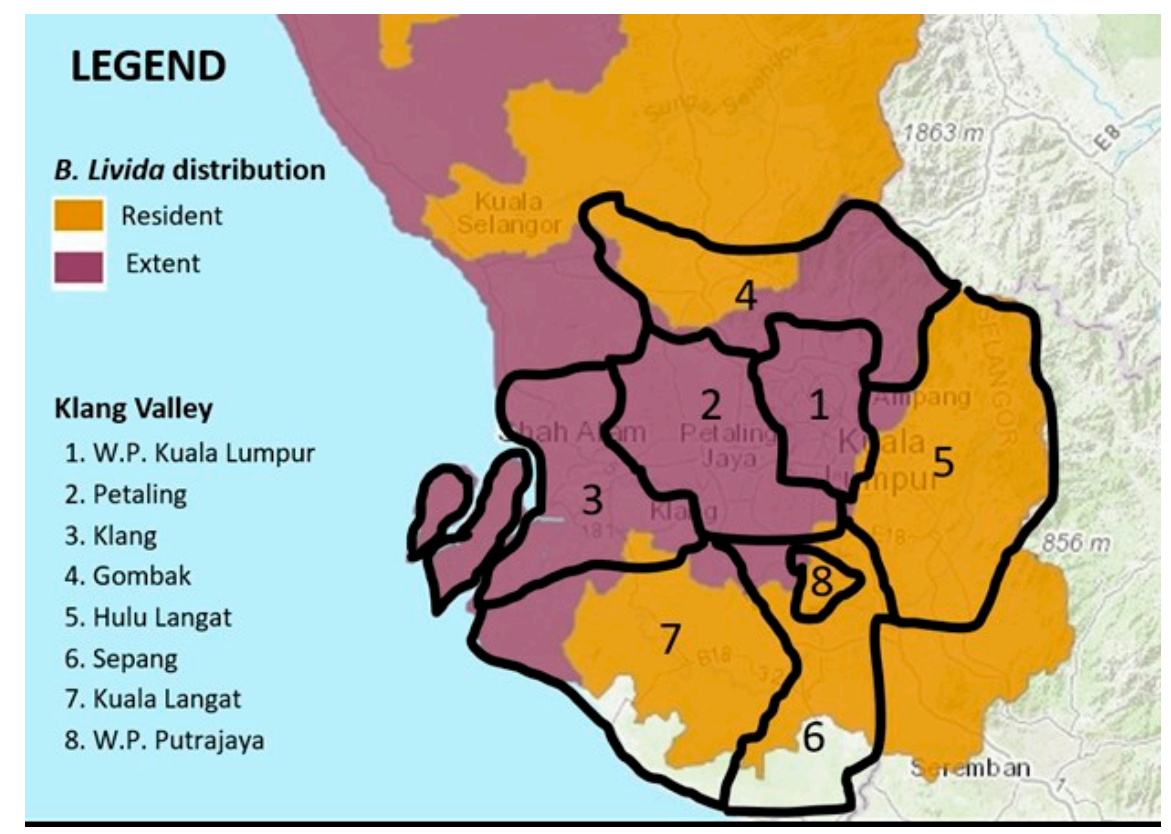

Figure 2. Study Area and B. livida hotspots [5].

An online survey was administered using a 'Google Form' circulated to the fish hobbyist groups on social media. Engaging with members ensured the platform algorithm because the survey posted on their social media feed was challenging. This was an issue expected by Ronald [16] when using the internet-based survey to increase response rates. Moreover, each hobbyist group is bombarded with over 20 new posts every day, reducing the chance of the survey appearing on their social media feeds. Support from admin moderators and group members were sought to distribute and circulate the survey post. However, the social group member seeing the survey post provides no guarantees that they will participate. Therefore, incentives might be a consideration in future studies to mitigate the issue of low participation.

A purposive sampling method was used in this study targeting fish hobbyists living in KV. A total of $N=150$ respondents were classified with a $90 \%$ confidence interval and a $6.6 \%$ margin of error. According to a conventional sample size formula like Cochrane [17], Yamane [18] and Zikmund [19], a sample size of at least $N=300$ respondents is required for a survey to represent the actual population. However, due to the lack of hobbyists in Klang Valley, lack of engagement in surveys and time constraints, this study used a smaller population sample size with less representation accuracy. Purposive sampling is a non-probability technique in 
which respondents are chosen based on qualities or expertise they possess [20]. In this case, the expertise is the hobbyists' familiarity with the target species.

Stebbins [21] argued that there was a distinction between amateurs, hobbyists and experts in leisure and recreational activities. Hobbyists spend a tremendous amount of time on leisure activities. In this study, 'hobbyist' was purposely characterised as public group members of fish hobbyist groups on social media, including betta breeders, goldfish keepers and aquascapers. Apart from these criteria, hobbyists also had to be residents of KV. The hobbyist group was selected because they are the primary stakeholders of the ornamental fish trade and are familiar with B. livida. Therefore, they are the group most likely to donate to B. livida conservation.

\subsection{Survey Instrument}

The survey started with general icebreakers regarding hobbyists' perceptions towards the species' value. Then, additional information concerning whether they had collected the species as a hobby and the mode and collection purpose was recorded as supportive facts. The survey continued with knowledge, perceptions and attitude towards B. livida conservation. Finally, the WTD section was introduced. The survey ended by eliciting the demographic background of respondents.

In the knowledge section, multiple-choice questions were developed to gauge their knowledge of the species. Study of the Golden Warbler [22] established that general knowledge of the species significantly affected the respondent's WTP for species conservation. Respondents were firstly shown pictures portraying various betta species and they had to choose the correct image of B. livida. Furthermore, they were questioned whether they knew of $B$. livida in $\mathrm{KV}$, the species habitats and further analysis of conservation and IUCN status. The mean score represents the hobbyists' knowledge regarding the conservation of $B$. livida.

Next, hobbyists responded to Likert-type scaled questions with a score for a series of perception statements contributing to WTD for the species conservation. The questions ollowed the example provided by Shahwahid et al. [13]. Statements covered perceptions of ecology, biodiversity and heritage niche of the species were included. Then, the best possible ways for species conservation were covered. Protection of the species habitat should be prioritised, but translocation to new habitats could also serve as an alternative to conservation. Some betta breeders have done captive breeding and released them back to the wild to foster natural stocks. Respondents were also questioned regarding the effort of authorities and the existing legislation to protect the species. The last statement sets in the survey addressed the possible reasons for species endangerment.

Likert scaled questions were also applied in the attitude section, where hobbyists responded to possible attitude statements. Their views towards nearby wildlife indicated that they were affected by experience and had preferences for particular species [23]. Hence, it was prudent to ask hobbyists if they had dedicated themselves to species conservation by researching their willingness to collect wild B. livida or purchase captive breeds. Catching the species is one of the factors threatening the species; the tendency of refraining and preventing others from catching the species in the wild was also included in survey questions. This section also measured the hobbyist's concerns regarding the dwindling wild species population and their habitat degradation. The following two sets identify their potential to contribute to the monetary fund or expertise in conservation. The final question sets dealt with controversial measures in protecting wildlife related to regulations and the feasibility of getting a licence to own the species.

A manuscript called 'Wild Red Fighting Fish, a Klang Valley Natural Heritage' was initially presented to hobbyists in the WTD section. The text discussed the unique characteristics of B. livida and its market in the ornamental fish trade. The North Kuala Langat Forest Reserve was an example of the degradation of the species' habitat, which has led to the endangerment of the wild species population. Readers were then told about monetary funds that were crucial in developing conservation plans for the species, such as gazetting habitats, breeding and awareness programmes. With all the details collected, questions 
emerged as to whether they were willing to donate (WTD) a set amount annually for B. livida conservation.

Double bound dichotomous key questions were developed to probe hobbyists' WTD for species conservation [24]. A total of five (5) sets of different bids were presented to respondents starting from RM1, RM3, RM5, RM7 and RM9, respectively, based on the pilot test. The WTD questions were double-bounded; when respondents accepted the first bid (BID1), a second bid (BID2) with a higher amount was introduced and they had to accept or reject the bid. If the respondent refused BID1, BID2 was presented with a lower amount and had to accept or reject the offer. Respondents were free to reject the entire bid. Possible reasons for each outcome were probed.

The last section of the survey gathered social background data from the respondents, including age, gender, marital status, race, education level, occupation and household income. These data were critical to compare with population census data. KV districts were also noted as within the targeted sample population. Out-group respondents were removed from this sample size.

\subsection{Validity and Reliability}

The questionnaire was validated by a panel of three experts with expertise in wildlife valuation and perception studies. A four-point scale rating with $1=$ Not Relevant, 2 = Somewhat relevant, 3 = Relevant, 4 = Very relevant was used for expert scoring. Only items that scored more than two were retained. Furthermore, the comments and suggestions by the reviewers were taken into consideration to further improve the questionnaire. Next, a reliability test was done on hobbyists' perception and attitude towards species conservation involving $N=30$ pilot respondents. Validation was assessed based on the survey format and contents to verify external and internal inconsistencies. The reliability of the survey was based on the Kuder-Richardson coefficient of reliability (K-R 20) test for the knowledge section and the Cronbach's alpha test for the perceptions and attitudes section to ensure that item questions on each section represent the best score for each attribute. The reliability of knowledge component was K-R $20=0.46$, which was the rule for moderate agreement [25]. Perception was $\alpha=0.54$, which was lower than the average standard. However, reviews from various papers showed that an $\alpha=0.5$ can be satisfactory and sufficient (see Taber, 2018); thus, the score of $\alpha=0.54$ was considered acceptable. In comparison, the attitude section was $\alpha=0.78$, which was universally used in most studies.

\subsection{Data Analysis and Model Specification}

Descriptive analysis was conducted on general questions, perception and attitude towards species conservation and the respondents' social demographics using SPSS v23. Frequency means and percentages were tabulated to reflect the attributes.

WTD questions were analysed using STATA v15. Probit regression was conducted using WTP11 and WTP2 data. This model was chosen because of its well-established theoretical background and its compatibilities with dichotomous variables. The model Equation (1) is illustrated as follows:

$$
\mathrm{WTPi}=\ln \left(\frac{P}{1-P}\right)=\beta 0+\beta 1 \mathrm{X} 1+\beta 2 \mathrm{X} 2 \ldots \beta \mathrm{n} \mathrm{n}
$$

where $P=$ the probabilities, $Y=1, X$ is a set of independent variables, $\beta$ is the coefficient to be estimated corresponding to the logistic distribution. Thus, WTP depends on various factors, including bid price and unobservable characteristics to be captured in error ( $\varepsilon i$ ). Hobbyists were then given a follow-up WTP question:

$$
\begin{gathered}
\text { WTPi }=\mathrm{Xi} \beta+\varepsilon \mathrm{i} \\
\mathrm{WTP} 2 \mathrm{i}=(1-\mathrm{y}) \mathrm{WTPi}+\mathrm{Y} \beta+\delta
\end{gathered}
$$


In which $\mathrm{Y}$ is the parameter on the starting bid $\beta \mathrm{i}$, while $\delta$ is a shifting parameter. Therefore, hobbyists were questioned for double intervals. WTP $=\beta 2$ accepts both starting bid $\beta 1$ and a follow-up bid $(\beta 2), \beta 2 \leq \mathrm{WTP}<\beta 1$ rejects the starting bid $(\beta 1)$ and accepts the follow-up bid $(\beta 2)$, or WTP $<\beta 2$ rejects both bids $(\beta 1)$, followed by $(\beta 2)$. From the possible choices, the sequences are as follows (3):

$$
\begin{gathered}
\mathrm{Li}\left(\frac{\mathrm{WTPi}}{\beta 1}\right)=\operatorname{Pr}(\mathrm{WTP} 1 \mathrm{i}+\varepsilon \mathrm{ij}>\beta \mathrm{i} \mathrm{WTP} 2+\varepsilon 2 \mathrm{j} \geq \beta 2) \mathrm{YY} \\
\operatorname{Pr}(\mathrm{WTP} 1 \mathrm{i}+\varepsilon \mathrm{ij}>\beta \mathrm{i} W T P 2+\varepsilon 2 \mathrm{j} \geq \beta 2) \mathrm{YN} \\
\operatorname{Pr}(\mathrm{WTP} 1 \mathrm{i}+\varepsilon \mathrm{ij}>\beta \mathrm{i} W T P 2+\varepsilon 2 \mathrm{j} \geq \beta 2) \mathrm{NY} \\
\operatorname{Pr}(\mathrm{WTP} 1 \mathrm{i}+\varepsilon \mathrm{ij}>\beta \mathrm{i} W T P 2+\varepsilon 2 \mathrm{j} \geq \beta 2) \mathrm{NN}
\end{gathered}
$$

WTPi and WTP2 are the means for the first and latter bid response, while YY= yes-yes and $\mathrm{YN}=\mathrm{I}$ for a yes-no answer and NY for a no-yes answer, NN $=0$ for no-no answer. This likelihood function is then estimated using the following model (4):

$$
\mathrm{Li}\left(\frac{\mathrm{WTPi}}{\beta \beta 1}\right)=\varnothing \frac{\varepsilon}{\varepsilon 2}\left(\mathrm{~d} 1 \mathrm{j}\left(\frac{\beta 1-\mathrm{WTP} 1}{\sigma 1}\right) \mathrm{d} 2 \mathrm{j}\left(\frac{\beta 2-\mathrm{WTP} 2}{\sigma 2}\right), \mathrm{d} 1 \mathrm{jd} 2 \mathrm{j} \rho\right)
$$

In which WTP1J = 1 if the hobbyist answered the first question yes or WTP2J if the response to the second question was yes or otherwise, $\operatorname{dij}=2 \mathrm{WTP} 1 \mathrm{j}=1$ and $2 \mathrm{WTP} 2 \mathrm{j}=1$. Thus, the mean (5) and median (6) are derived as follow:

$$
\begin{gathered}
\text { Mean WTP }=\exp \left(\frac{\hat{X \hat{\beta}}}{\hat{\beta} 0}+0.5 \hat{\sigma} 2\right) \\
\text { Median WTP }=\left(\frac{\bar{X} \beta^{\prime}}{\hat{\beta} 0}\right)
\end{gathered}
$$

where $\mathrm{X}$ is a $\mathrm{k}+1$ row vector of the mean value of the possible variable, including 1 for constant term, $\beta$ is a $k+1$ column vector of estimated coefficient and $\hat{\sigma}$ is the estimated variance. Alejandro (2012) [24] argued that using this double-bound method enables the efficient utilisation of data to estimate WTP (or, in this case, WTD).

The model below shows factors influencing the WTD of hobbyists to conserve wild $B$. livida in Klang Valley (see Table 2). The WTP elicitation method to be used for dependent variables is consistent with single-bound CVM and double-bound CVM.

$$
\mathrm{WTD}=\beta 0+\beta 1 \mathrm{BID}+\beta 2 \mathrm{AGE}+\beta 3 \mathrm{INC}+\beta 4 \mathrm{KNOW}+\beta 5 \mathrm{PERC}+\beta 6 \mathrm{ATT}+\varepsilon
$$

Table 2. Variables used in the WTD model.

\begin{tabular}{ccc}
\hline WTD & $\begin{array}{c}\text { Willingness to Donate (MYR) } \\
\text { (1: Yes, 0: No) }\end{array}$ & Dependent Variable \\
\hline B0 & Constant Coefficient & \\
BID 1 & Initial bids & Independent variable \\
BID 2 & Follow up bids & Independent variable \\
AGE & Age of hobbyist & Independent variable \\
INC & Household Income of hobbyist & Independent variable \\
KNOW & Knowledge of the B. livida conservation & Independent variable \\
PERC & Perception towards the species conservation & Independent variable \\
ATT & Attitude towards the species conservation & Independent variable \\
OWNB & Owned B. livida (1: Yes. 0: No) & Independent variable \\
$\varepsilon$ & Random error & \\
\hline
\end{tabular}




\section{Results and Discussion}

\subsection{Social Demographics and General Question}

Social demographics data of hobbyists were collected as the foundation of this study. Table 3 below displays the demographics summary of the respondents:

Table 3. Hobbyists' social demographics background.

\begin{tabular}{|c|c|c|c|}
\hline & Item & Frequency & $\%$ \\
\hline \multirow[t]{3}{*}{ F1 } & Gender & & \\
\hline & Male & 142 & 94.7 \\
\hline & Female & 8 & 5.3 \\
\hline \multirow[t]{5}{*}{ F2 } & Age & & \\
\hline & $21-30$ & 60 & 40.0 \\
\hline & $31-40$ & 72 & 48.0 \\
\hline & $41-50$ & 17 & 11.3 \\
\hline & $>51$ & 1 & 0.7 \\
\hline \multirow[t]{4}{*}{ F3 } & Marital Status & & \\
\hline & Married & 104 & 69.3 \\
\hline & Single & 45 & 30.0 \\
\hline & Others & 1 & 0.7 \\
\hline \multirow[t]{4}{*}{ F4 } & Race/Ethnicity & & \\
\hline & Malay & 124 & 82.7 \\
\hline & Chinese & 19 & 12.7 \\
\hline & Indian & 7 & 4.7 \\
\hline \multirow[t]{9}{*}{ F5 } & The district within $\mathrm{Kl}$ & Valley & \\
\hline & Petaling & 28 & 18.7 \\
\hline & Hulu Langat & 27 & 18.0 \\
\hline & Klang & 26 & 17.3 \\
\hline & Kuala Lumpur & 22 & 14.7 \\
\hline & Gombak & 16 & 10.7 \\
\hline & Sepang & 14 & 9.3 \\
\hline & Kuala Langat & 9 & 6.0 \\
\hline & Putrajaya & 8 & 5.3 \\
\hline \multirow[t]{6}{*}{ F6 } & Education level & & \\
\hline & Bachelor's Degree & 57 & 38.0 \\
\hline & Diploma and Equivalent & 45 & 30.0 \\
\hline & High school & 34 & 22.7 \\
\hline & Master's Degree & 13 & 8.7 \\
\hline & $\mathrm{PhD}$ & 1 & 0.7 \\
\hline \multirow[t]{5}{*}{ F7 } & Occupation & & \\
\hline & Private & 81 & 54.0 \\
\hline & Government & 38 & 25.3 \\
\hline & Self-Employed & 28 & 18.7 \\
\hline & Student & 3 & 2.0 \\
\hline \multirow[t]{5}{*}{ F8 } & Household Income Category & & \\
\hline & B40 (lower than RM4500/Month) & 84 & 56.0 \\
\hline & M20 (between RM4501-RM10,000/month) & 55 & 36.7 \\
\hline & T20 (higher than RM10,001/month) & 10 & 6.7 \\
\hline & No Income & 3 & 0.7 \\
\hline
\end{tabular}

Most (94.7\%) respondents were male, indicating that men conduct this hobby in higher numbers. Almost half of respondents were between 31 and 40 years of age (48\%) and most were married (69.3) middle-aged men. Race composition reveals that Malay was the majority $(82.7 \%)$, followed by Chinese $(12.7 \%)$ and Indian $(7 \%)$. The highest education level reported was a bachelor's degree at 38\%. Interestingly, diploma and high school graduates exhibited weights of $30 \%$ and $22.7 \%$, respectively. This explains why most 
respondents were in the B40 income category (56\%). In terms of employment, most worked in the private sector (54\%), followed by the government sector $(25 \%)$ and self-employed sector $(18 \%)$. The hobbyist distribution was almost evenly distributed within Klang Valley. The Petaling district (18.7\%) contained marginally more than Hulu Langat district (18\%). However, 33 respondents were removed from the total sample because they were not within the study area. Feedback from the out-group willing to participate in this online survey was also encouraging, intending to broaden the scope of future study.

The initial section of the survey stipulated several general questions regarding hobbyists' leisure activities. This information may be crucial for building a fundamental understanding of the nature and essence of this study. Therefore, the results in Table 4 below were tabulated so that the mode percentage frequency is of the upper-class.

Table 4. Result for general questions.

\begin{tabular}{|c|c|c|c|}
\hline & Item & Frequency & $\%$ \\
\hline \multirow[t]{3}{*}{ A1 } & Owned B. livida $(N=150)$ & & \\
\hline & NO & 85 & 56.70 \\
\hline & YES & 65 & 43.30 \\
\hline \multirow[t]{4}{*}{ A2 } & Mode of Obtaining $B$. livida $(N=65)$ & & \\
\hline & Self-Caught & 37 & 46.3 \\
\hline & Private Seller & 32 & 40.0 \\
\hline & Aquarium/Pet shop & 11 & 13.8 \\
\hline \multirow[t]{4}{*}{ A3 } & Reason for Owning $(N=65)$ & & \\
\hline & Hobby & 44 & 47.3 \\
\hline & Breeding & 39 & 41.9 \\
\hline & Selling & 10 & 10.8 \\
\hline \multirow[t]{4}{*}{ A4 } & No. of B. livida owned $(N=65)$ & & \\
\hline & $1-10$ owned & 46 & 70.7 \\
\hline & 11-50 owned & 9 & 13.8 \\
\hline & $>51$ owned & 10 & 14.6 \\
\hline \multirow[t]{5}{*}{ A5 } & A reason not owning $B$. livida $(N=85)$ & & \\
\hline & Difficult to Obtain & 45 & 52.9 \\
\hline & Not Interested & 28 & 32.7 \\
\hline & Very Expensive & 11 & 12.8 \\
\hline & Others & 1 & 1.7 \\
\hline \multirow[t]{5}{*}{ A6 } & Value Perceived towards the species $(N=150)$ & & \\
\hline & Bequest Value & 90 & 60.0 \\
\hline & Biodiversity Value & 45 & 30.0 \\
\hline & Economic Value & 14 & 9.3 \\
\hline & Other & 1 & 0.7 \\
\hline
\end{tabular}

Almost half $(56.7 \%)$ of respondents $(N=150)$ owned $B$. livida and most caught the species themselves in the wild (46.3\%), followed by purchasing from private sellers $(40 \%)$ and pet shops (13.8\%). This trend has highlighted concerns for an unregulated and excessive catch of wild betta by $\mathrm{Ng}$ [6]. Overexploitation could further endanger and jeopardise the conservation status of the species. This survey could not determine the hobbyist's 'hotspot' for the species' wild catch, which could provide crucial insights in monitoring the wild catch activities, especially the species distribution in forest reserves and private lands. It must be noted, however, that $41.9 \%$ of the species owners breed them. Most wild bubblenester betta like $B$. livida already have established breeding programs, producing offspring like the common colourful Siamese betta. However, the success of reproducing the species may vary based on the number of $B$. livida they own. The majority own 1-10 betta fishes $(70.7 \%)$, although this figure does not distinguish among the numbers of $B$. livida caught in the wild and the ones that are bred or purchased. On the other hand, hobbyists who did not own the species explained why they (52.9\%) have difficulty obtaining the B. livida, 
followed by a lack of interest in the species and the high cost. Hobbyists also responded concerning the value of species and over half said it was of bequest value $(60 \%)$ and that it should be protected for future generations.

\subsection{Knowledge}

The knowledge section assessed the respondent's knowledge of species conservation based on their mean score for each item question, as shown in Table 5. Thus, the knowledge in this survey did not reflect the actual knowledge of respondents but rather represents their familiarity with the subject.

Table 5. Hobbyist's knowledge of B. livida Conservation.

\begin{tabular}{|c|c|c|c|c|c|c|}
\hline & \multirow[t]{2}{*}{ Item } & \multicolumn{2}{|c|}{ Frequency \% } & \multirow[t]{2}{*}{ Mean } & \multirow[t]{2}{*}{ Sd } & \multirow[t]{2}{*}{ Variance } \\
\hline & & 1 & $\mathbf{0}$ & & & \\
\hline B1 & Identified B. livida & 94.0 & 6.00 & 0.94 & 0.24 & 0.06 \\
\hline B2 & Existence of the Species in KV & 68.0 & 32.0 & 0.68 & 0.47 & 0.22 \\
\hline B4 & Meaning of Endemic & 22.0 & 78.0 & 0.78 & 0.42 & 0.17 \\
\hline B5 & Species Habitat & 94.70 & 5.30 & 0.95 & 0.23 & 0.05 \\
\hline B6 & IUCN Status & 48.70 & 51.30 & 0.51 & 0.5 & 0.25 \\
\hline B7 & Possible Reason for IUCN Status & 22.70 & 77.30 & 0.77 & 0.42 & 0.18 \\
\hline B8 & Meaning of Species Conservation & 15.30 & 84.70 & 0.85 & 0.36 & 0.13 \\
\hline \multirow[t]{2}{*}{ B9 } & Authorities & 31.30 & 68.70 & 0.69 & 0.47 & 0.22 \\
\hline & \multicolumn{3}{|c|}{ Average total mean knowledge } & 0.77 & & \\
\hline
\end{tabular}

The results indicate that most hobbyists can identify the picture of B. livida, among other betta species, with a mean of 0.94 and a slight variance of 0.06 . In addition, the betta species have distinguishing features, which was evident in that respondents were not confused with almost identical looking species, such as B. coccina and B. brownorum.

Only $68 \%$ of respondents knew that $B$. livida existed in KV areas. However, they have an average comprehension of what endemic species means and recognised the species natural habitat. Hobbyists could also grasp the meaning of species conservation and acknowledge species protection by an authority like the Department of Fisheries (DoF).

Half of the respondents were uncertain about the IUCN status for the species (51.3\%) with a significant standard deviation and variance. However, they can guess that conservation is due to the species' endemic nature, habitat degradation and exploitation. However, the conservation status of this species is one of the main problem statements for this study that is supposed to influence the WTD. It must be noted as well the mode in which the hobbyists gathered information regarding the species in Table 6, with social media being the most frequent source followed by websites. This study, therefore, justified the purposive sampling technique on hobbyist groups on social media.

Table 6. Information obtaining modes.

\begin{tabular}{cccc}
\hline B3 & Mode & Frequency & \% \\
\hline Media Social & 79 & 30.74 \\
Website/Internet & 64 & 24.90 \\
Friends/Relatives & 53 & 20.62 \\
Books & 34 & 13.23 \\
Exhibition & 27 & 10.51 \\
\hline
\end{tabular}

\subsection{Perception}

Perception is a means of interpreting, understanding or regarding something. Frequency in Table 7 below shows the hobbyists' response to the perception of wild B. livida conservation in Klang Valley: 
Table 7. Hobbyist's perception towards B. livida conservation.

\begin{tabular}{lcccccccc}
\hline & \multicolumn{7}{c}{$\boldsymbol{N}=\mathbf{1 5 0}$} & \multicolumn{3}{c}{ Frequency $\mathbf{0}$} & & Mean & Score \\
\cline { 2 - 8 } & & $\mathbf{1}$ & $\mathbf{2}$ & $\mathbf{3}$ & $\mathbf{4}$ & $\mathbf{5}$ & & \\
\hline C1 & Ecological Niche & 1.3 & 4.0 & 19.3 & 20.0 & 55.3 & 4.24 & 4 \\
C2 & Biodiversity Role & 0 & 0 & 2.7 & 19.3 & 78.0 & 4.75 & 4 \\
C3 & Natural Heritage & 0.7 & 0.7 & 2.7 & 18.0 & 78.0 & 4.72 & 4 \\
C4 & Preserving Habitat & 0.7 & 0 & 2.0 & 16.7 & 80.7 & 4.77 & 4 \\
C5 & Translocation & 33.3 & 14.0 & 24.0 & 12.0 & 16.7 & 2.65 & 3 \\
C6 & Captive Breeding & 7.3 & 11.3 & 35.3 & 27.3 & 18.7 & 3.39 & 3 \\
C7 & Authority Effort & 30.7 & 24.7 & 29.3 & 5.3 & 10.0 & 2.39 & 3 \\
C8 & Wildlife Law & 16.0 & 16.0 & 36.0 & 17.3 & 14.7 & 2.99 & 3 \\
C9 & Habitat Destruction & 0.0 & 0.7 & 4.0 & 15.3 & 80.0 & 4.75 & 4 \\
C10 & Exploitation & 11.3 & 7.3 & 19.3 & 20.7 & 41.3 & 3.73 & 3 \\
\hline
\end{tabular}

Note: $<2.00$ = strongly disagree (1), 2.01-3.00 = disagree (2), 3.01-4.00 = agree (3), 4.01-5.00 = strongly agree (4) (adapted from Pallant, 2007).

Hobbyists firmly agreed with the perception statements that B. livida habitat was the leading cause of the species endangerment (mean $=4.75)$, followed by the importance of preserving the species' habitat (mean $=4.24)$. They also strongly agreed that it was essential to protect the species because of its role in ecological niches, biodiversity enrichment, in addition to being part of the natural heritage of the state of Selangor. This way of thinking has to do with the fact that they are aware of the species' habitat. The notion of captive breeding was agreeable (mean $=3.39$ ), indicating that hobbyists were perceived as viable conservation options. Captive breeding increases survival for the species population but opens the door to the commercial market. In-depth research is needed to characterise the hobbyists' perception of captive breeding. However, respondents disagreed with the notion of transferring the species to new safe habitats (mean $=2.65$ ), which shows intense perception about the importance of the existing species habitat. The high variance means of 2.149 on this item should also be noted among other perception components. Respondents also argued that they did not have faith in current wildlife law to protect the species or in efforts by the authorities to conserve the wild B. livida population, with mean values of 2.39 and 2.99, respectively. The survey shows that overall, the hobbyist showed an agreeable perception about the species conservation (total average mean=3.83). However, they are hesitant about how management of the conservation will be conducted.

\subsection{Attitude}

Attitude is a mental state of mind that characterises an individual towards a subject. Table 8 shows the hobbyist's attitudes towards the B. livida conservation.

Table 8. Hobbyist's attitude towards B. livida conservation.

\begin{tabular}{|c|c|c|c|c|c|c|c|c|}
\hline & \multirow[t]{2}{*}{$N=150$} & \multicolumn{5}{|c|}{ Frequency $\%$} & \multirow[t]{2}{*}{ Mean } & \multirow[t]{2}{*}{ Score } \\
\hline & & 1 & 2 & 3 & 4 & 5 & & \\
\hline D1 & Stop buying Wild & 8.0 & 6.7 & 29.3 & 13.3 & 42.7 & 3.76 & 3 \\
\hline D2 & Only buy Captive Breed & 4.7 & 2.7 & 22.0 & 22.0 & 48.7 & 4.07 & 4 \\
\hline D3 & Refrain Wild Catch & 2.0 & 3.3 & 22.0 & 20.7 & 52.0 & 4.17 & 4 \\
\hline D4 & Advise People & 3.3 & 2.7 & 24.7 & 26.7 & 42.7 & 4.03 & 4 \\
\hline D5 & Concern (population loss) & 0.7 & 0.0 & 8.7 & 20.7 & 70.0 & 4.59 & 4 \\
\hline D6 & Concern (Habitat loss) & 0.7 & 0.7 & 6.0 & 16.0 & 76.7 & 4.67 & 4 \\
\hline D7 & Contribute Financially & 7.3 & 1.3 & 34.7 & 26.7 & 30.0 & 3.71 & 3 \\
\hline D8 & Helping Researcher & 3.3 & 1.3 & 25.3 & 28.7 & 41.3 & 4.03 & 4 \\
\hline D9 & Rules and Regulation & 6.0 & 3.3 & 18.0 & 17.3 & 55.3 & 4.13 & 4 \\
\hline D10 & Ownership License & 23.3 & 8.0 & 16.0 & 19.3 & 33.3 & 3.31 & 3 \\
\hline
\end{tabular}

Note: $<2.00=$ strongly disagree (1), 2.01-3.00 = disagree (2), 3.01-4.00 = agree (3), 4.01-5.00 = strongly agree (4) (adapted from Pallant, 2007). 
The hobbyists were firm on their commitment to purchase wild B. livida (mean $=3.76$ ). However, they appeared to be firmly in agreement to buy a captive-bred fish instead of wild caught fish (mean $=4.07$ ). This corresponds to the initial understanding of the captive breeding species. The response also showed that they firmly decided to withdraw from capturing betta from the wild and were happy to advise others to join or support the initiative. This is a strong indication for hobbyists to withdraw from a wild catch. The initial results data indicated that most of the respondents that owned B. livida had caught the betta from the wild. This may also be the explanation of why the hobbyists tended to purchase a captive-bred fish. Hobbyists demonstrated considerable concern (strongly agreed) for both biodiversity losses $($ mean $=4.67)$ and the dwindling population of species $($ mean $=4.59)$ compatible with previous views of habitat and exploitation. Consensus respondents on the willingness to make a charitable contribution (mean $=3.71$ ) will possibly affect the WTD section. In addition, they have strongly agreed to support biodiversity protection by enabling the researchers to obtain valuable data (mean $=4.03$ ). This shows a positive attitude by the hobbyist in conserving the species.

Concerning governance from authorities, the hobbyists must comply with the laws and regulations laid down for the species. Therefore, they consented to comply with the ownership licence provision for B. livida. It should be noted, based on the feedback, that some respondents strongly object to the requirement for a species ownership licence, which was confirmed by the significant variance mean for this item (2.458) relative to other attitude items. However, the survey could not differentiate between those who accepted or opposed this notion: hobbyists, breeders, or sellers. Therefore, further in-depth research is required to validate this inference and probe why they are against licencing.

\subsection{Willingness to Donate}

The survey documented the hobbyist's willingness to donate to wild B. livida conservation in Klang Valley by utilising closed-ended dichotomous key questions. Table 9 indicates the frequency of those who are eager or unwilling to do so:

Table 9. Hobbyist WTD for Wild B. livida Conservation.

\begin{tabular}{cccc}
\hline & Item & Frequency & $\%$ \\
\hline E1 & & Willingness to Donate $(N=150)$ & \\
& YES & 99 & 66 \\
& NO & 51 & 44 \\
\hline E5 & Bequest & Reason for WTD $(N=99)$ & \\
& Conservation & 59 & 59.5 \\
& Others & 38 & 38.4 \\
& & 2 & 2.1 \\
\hline E6 & & Reason NOT WTD $(N=51)$ & \\
& Want to Contribute with Other Mean & 27 & 52.9 \\
& Could not Afford & 18 & 35.3 \\
& It is unnecessary & 6 & 11.8 \\
\hline
\end{tabular}

The majority of the hobbyists who participated in this survey were willing to contribute $(66 \%)$ to conserve the species and vice versa (44\%). Furthermore, they are ready to donate because of the importance of the species' perceived bequest value $(59.5 \%)$. This corresponded to the earlier finding that hobbyists preferred this species to be a natural heritage and want future generations to appreciate it. Therefore, the donation should be used solely for the conservation of the species (38.4\%). In addition, hobbyists were willing to contribute because of the species' aesthetic value (2.1\%). On the other hand, a significant number of hobbyists opted not to donate because they wanted to participate by other methods (52.9\%), which, backed by the mindset of most respondents, firmly consent to aid the researcher with conservation efforts. Other factors include the possibility that they cannot afford a contribution or consider a B. livida reservation unnecessary. 
Probit regression analysis of single bound CVM for initial bid (BID1) against WTD was performed and tabulated, as shown in Table 10.

Table 10. Single Bound CVM.

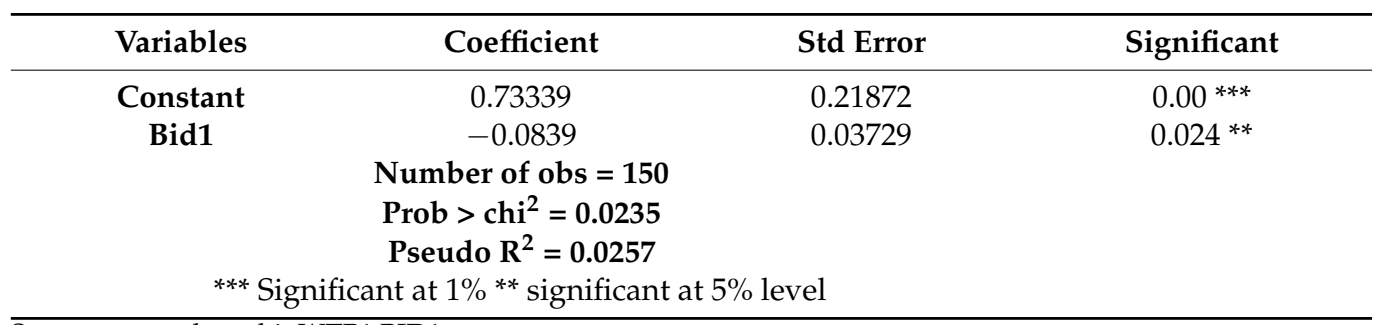

Stata command: probit WTP1 BID1.

The results revealed that the initial bid negatively impacted WTD, indicating that BID1 has an inverse relationship with WTD. According to demand theory, the value was expected to be significant at a $5 \%$ level (0.024). $\mathrm{R}^{2}$ showed that $2.5 \%$ of the initial bid as a dependent variable influences the WTD. Further Probit analysis with independent variables of age and income of the respondents, along with the hobbyists' mean for knowledge, perception and attitude towards the species conservation, was conducted and shown in Table 11:

Table 11. Single-bound CVM modified.

\begin{tabular}{cccc}
\hline Variables & Coefficient & Std Error & Significant \\
\hline Constant & -1.06396 & 0.6215333 & 0.087 \\
BID1 & -0.0731149 & 0.0383354 & $0.05^{* *}$ \\
AGE & 0.0643578 & 0.0200888 & $0.001^{* * *}$ \\
INC & -0.0000623 & 0.0000321 & $0.05^{* *}$ \\
& Number of obs $=\mathbf{1 5 0}$ & \\
& Prob $>\mathbf{c h i}^{\mathbf{2}}=\mathbf{0 . 0 0 1 0}$ & & $* * *$ significant at $1 \%$ \\
& Pseudo $\mathbf{R}^{\mathbf{2}}=\mathbf{0 . 0 8 1 6}$ & & $* *$ significant at $5 \%$ \\
\hline
\end{tabular}

Stata Command: probit WTP1 BID1 AGE INC.

Independent variables indicated that they influenced the result of WTD by $8.2 \%$. At Single bound CVM, all independent variables of respondents were not significant, except for age and income. However, the respondents' age was significant at $1 \%$ level. In comparison, income was significant at 5\%, indicating that the older the respondents were, the higher the possibility to donate. Significances from these variables, compute for WTD value for initial bid, was estimated using the WTD estimation model, as shown in Table 12.

Table 12. Estimation of WTD using Single-Bound CVM.

\begin{tabular}{|c|c|c|c|}
\hline & Coefficient & Std Error & Significant \\
\hline WTD1 & 9.351782 & 2.682928 & $0.000^{* * *}$ \\
\hline
\end{tabular}

The WTD single bound for the survival of wild $B$. livida was estimated at a value of RM9.35 per year. This figure will function as a conservation work fund for the species. For the second bid submitted to the respondent, a double-bound CVM was used to evaluate both the original and the second bid for WTD species, as shown in Table 13: 
Table 13. Double-Bound CVM.

\begin{tabular}{cccc}
\hline Variables & Coefficient & Std Error & Significant \\
\hline Beta Constant & 8.947126 & 1.41945 & $0.000^{* * *}$ \\
Sigma Constants & 14.4819 & 2.117302 & $0.000^{* * *}$ \\
\hline Number of obs $=\mathbf{1 5 0}$ & & \\
Prob $>$ chi2 $=\mathbf{0 . 0 0 0 0}$ & & \\
\hline Stata command: doubleb BID1 BID2 WTP1 WTP2; ${ }^{* * *}$ significant at 1\%.
\end{tabular}

The table revealed that the initial and the second bids were relevant at $1 \%$, with a favourable relationship with WTD. The discrepancy between Beta and Sigma constant (bids) was RM5.53. Independent variables were then applied to the model to evaluate some critical relationships with the WTD, as shown in Table 14:

Table 14. Double-bound CVM modified.

\begin{tabular}{|c|c|c|c|}
\hline Variables & Coefficient & Std Error & Significant \\
\hline Constant & -15.84793 & 7.400414 & 0.032 \\
\hline AGE & 0.6987584 & 0.2270002 & $0.002^{* * *}$ \\
\hline OWNB & 5.400544 & 2.912554 & $0.064 *$ \\
\hline Sigma Constant & 14.02604 & 2.048678 & 0.000 \\
\hline \multicolumn{4}{|l|}{ Number of obs $=150$} \\
\hline \\
\hline \multicolumn{4}{|c|}{ Prob $>\mathrm{chi}^{2}=0.0018$} \\
\hline \multicolumn{4}{|c|}{ * Significant at $10 \%$ level $* * *$ Significant at $1 \%$ level. } \\
\hline
\end{tabular}

In contrast to a single bound CVM earlier, the double-bound CVM has no significant effect on the WTD. However, species-owned hobbyists (OWNB) have a considerable influence at a $10 \%$ level. This was focused on the notion that those who possessed B. livida were more inclined to donate and vice versa. The respondent's age was the only reliably significant $1 \%$ positive relationship with WTD using a double-bound model. Subsequently, significant variables were estimated in the WTD estimation model using a double-bound CVM, as shown in Table 15:

Table 15. Estimation of WTD using Double-Bound CVM.

\begin{tabular}{|c|c|c|c|}
\hline & Coefficient & Std Error & Significant \\
\hline WTD & 9.04 & 1.408674 & $0.000^{* * *}$ \\
\hline
\end{tabular}

Hobbyist's WTD for the B. livida conservation in Klang Valley was MYR 9.04 per year, estimated using double-bound CVM with independent attributes. This estimation comprises both initial and second bids to value a mean WTD. Hence, approximately MYR 1356 from 150 hobbyists in Klang Valley is expected to conserve wild B. livida per year. However, the annual funds for a conservation fund are often minimal. Thus, it must be spent effectively to ensure the survivability of the species.

In this analysis, local WTD for species-level was calculated to be higher than the WTP for elephants performed by Shahwahid et al. [13]. Using closed-ended bids combined with double-bound dichotomous bid keys makes it possible for the respondent to be impartial when stating a monetary value. Moreover, as this study only specified the conservation B. livida, not the other wild betta species, the economic value elicited was lower than the survey by Teh et al. [14] and Vianna et al. [15]. However, their WTP was elicited towards various marine turtles and shark species and they gave more weight for the respondent to consider their willingness to pay for conservation. The mean WTD could also have 
been influenced by the number of respondents in this study. Moreover, those residing outside KV who could be informative were also excluded. Studies by Haefele et al. [7] and Michalski et al. [26] showed significance between two regions willing to conserve species in other areas.

Hobbyist's knowledge, perception and attitude did not significantly influence the WTD. Results for the hypotheses $\mathrm{H}_{\mathrm{A} 1}, \mathrm{H}_{\mathrm{A} 2}$ and $\mathrm{H}_{\mathrm{A} 3}$, assuming knowledge, perception and attitude of hobbyists influenced the WTD were rejected. Thus, the null hypothesis was accepted. This result contrasted with other established studies that independent variables influenced the WTD $[22,27,28]$. However, in the knowledge section, an item regarding the IUCN status of B. livida, despite only half of the respondents knew its endangered status, hobbyists were willing to donate for species conservation. This corresponded with Colléony et al. [29] that the respondents chose to donate not because of the endangerment status but rather because of the species' charisma and aesthetic. Age of hobbyist was the only variable that consistently and significantly influenced the WTD for conservation. According to Asmamaw et al. [12], age greatly affected the affordability to pay for protection. Older people tended to have more stable employment and income and are possibly more familiar with the theme. The income variable was significant for the single bound WTD but failed to influence double-bound bids significantly. Regression was computed for the age of hobbyists against knowledge perception and attitude and income, but they were also found not to be significant. However, hobbyists who owned B. livida (OWNB) were more likely to donate for species conservation than those who did not (significant). This was parallel with familiarity with the targeted species being able to influence WTP, as shown in the study by Lundberg et al. [28]. It suggests older hobbyists who are more familiar with B. livida are most likely to donate for species conservation for the sake of heritage value.

\section{Conclusions}

Degradation of natural ecosystems and over-exploitation of wild species in the commercial market have raised concerns regarding the endangerment and survival of the flora and fauna heritages of Klang Valley. Via this preliminary study, the hobbyist's knowledge, perception, attitude and willingness to donate to protect wild B. livida in Klang Valley was addressed using an online survey questionnaire. This study served as a baseline for WTD towards conserving wild betta and freshwater fish in Malaysia. This study also inferred that the Klang Valley hobbyists' WTD for wild B. livida conservation using double-bound CVM was MYR 9.05 per year. The hobbyist's knowledge, perception and attitude toward B. livida conservation have no significant relationship with the WTD.

In contrast, the respondent's age indicated a significant connection concerning the WTD, attributed to the species familiarity among older citizens. The possibility that owners of the species (OWNB) would contribute to its survival was also significant. It was also found that the number of wild species caught by the hobbyist appeared to be substantial, but the implications could not be established.

As a recommendation, the decision-makers should consider the amount of donation that the hobbyists are willing to contribute and set up a trust fund for habitat conservation for the species. Online donation collecting through social media has been proven a successful fundraising platform. Furthermore, the survey responses suggested that individual hobbyists could contribute to the parent-pair breeding programme for B. livida. For example, on transferring them for ex-situ conservation, i.e., captive breeding, some successfully bred and released the species back into their natural habitat. Therefore, the decision-makers should reach out to hobbyist groups and collaborate to preserve this valuable fauna.

This research has some weaknesses; future study could involve more respondents representing the hobbyist sample population. Next, the examination must be inclusive for respondents outside the species distribution region to determine any substantial variation. In addition, more exploration of the target species' charisma and aesthetic appeal must be included to assess respondent attraction to the species when it comes to donating for 
conservation. Lastly, it is recommended that this type of study be conducted on other significant local freshwater fish.

Author Contributions: Conceptualisation, M.F.A.R. and N.K.M.; Data curation, M.F.A.R. and N.K.M.; Formal analysis, M.F.A.R.; Investigation, M.F.A.R. and N.K.M.; Methodology, M.F.A.R.; Supervision, N.K.M.; Project administration, M.F.A.R.; Resources, M.F.A.R. and N.K.M.; Software, N.K.M.; Validation, N.K.M.; Writing—original draft, M.F.A.R.; Writing—review and editing, M.F.A.R. and N.K.M. All authors have read and agreed to the published version of the manuscript.

Funding: This research received no external funding; however, the Research Management Centre of Universiti Putra Malaysia will fund the publication fee.

Data Availability Statement: Not applicable.

Acknowledgments: We would like to thank those who have participated in this study, especially admin moderators of hobbyist groups, who have helped us to distribute this survey.

Conflicts of Interest: The authors declare no conflict of interest.

\section{References}

1. Tan, H.H.; Ng, P.K.L. The fighting fishes (Teleostei: Osphronemidae: Genus Betta ) of Singapore, of Malaysia and Brunei. Raffles Bull. Zool. 2005, 13, 43-99.

2. Keat-Chuan, N.C.; Aun-Chuan, O.P.; Wong, W.L.; Khoo, G. An overview of the status, trends and challenges of freshwater fish research and conservation in Malaysia. J. Surv. Fish. Sci. 2017, 3, 7-21. [CrossRef]

3. Chan, K.-G. Conservation of the critically endangered endemic Malaysian black fighting fish Betta persephone Schaller (Teleostei: Osphronemidae): A brief review. PeerJ. Prepr. 2015, 3, e1048v1. [CrossRef]

4. Giam, X.; Koh, L.P.; Tan, H.H.; Miettinen, J.; Tan, H.T.W.; Ng, P.K.L. Global extinctions of freshwater fishes follow peatland conversion in Sundaland. Front. Ecol. Environ. 2012, 10, 465-470. [CrossRef]

5. $\quad$ Low, B.W. Betta livida. IUCN Red List. Threat. Species 2019, 8235. [CrossRef]

6. $\mathrm{Ng}, \mathrm{C}$. The ornamental freshwater fish trade in Malaysia. UTAR Agric. Sci. J. 2016, 2, 7-18.

7. Haefele, M.A.; Loomis, J.B.; Merideth, R.; Lien, A.; Semmens, D.J.; Dubovsky, J.; Wiederholt, R.; Thogmartin, W.E.; Gary, T.H.; Rodrigo, M.; et al. Willingness to Pay for Conservation of Transborder Migratory Species: A Case Study of the Mexican Free-Tailed Bat in the United States and Mexico. Environ. Manag. 2018, 62, 229-240. [CrossRef]

8. Martín-López, B.; Montes, C.; Benayas, J. Economic valuation of biodiversity conservation: The meaning of numbers. Conserv. Biol. 2008, 22, 624-635. [CrossRef]

9. Nijkamp, P.; Vindigni, G.; Nunes, P.A.L.D. Economic valuation of biodiversity: A comparative study. Ecol. Econ. 2008, 67, 217-231. [CrossRef]

10. Matsiori, S.; Aggelopoulos, S.; Soutsas, K. Economic value of conservation. The case of the edible sea urchin Paracentrotus lividus. J. Environ. Prot. Ecol. 2012, 12, 269-274.

11. Bandara, R.; Tisdell, C. The economic value of conserving the Asian elephant: Contingent valuation estimates for Sri Lanka. GAJAH J. Asian Elephant Spec. Gr. 2003, 22, 22-29.

12. Asmamaw, B.; Beyene, B.; Tessema, M.; Kara, A.; Goshu, B.; Assefa, A. Estimating Willingness to Pay for Labeobarbus fish Species Conservation in Lake Tana, Ethiopia: A Contingent Valuation Study. Int. J. Nat. Resour. Ecol. Manag. 2016, 1, 155-161. [CrossRef]

13. Shahwahid, M.; Yong, P.L.; Sius, T. Perceptions on wild elephants among the public in Pahang, Malaysia. Malays. For. 2009, 72, 37-44.

14. Teh, L.S.L.; Teh, L.C.L.; Jolis, G. An economic approach to marine megafauna conservation in the coral triangle: Marine turtles in Sabah, Malaysia. Mar. Policy 2017, 89, 1-10. [CrossRef]

15. Vianna, G.M.S.; Meekan, M.G.; Rogers, A.A.; Kragt, M.E.; Alin, J.M. Shark-diving tourism as a financing mechanism for shark conservation strategies in Malaysia. Mar. Policy 2018, 94, 220-226. [CrossRef]

16. Ronald, D. Fricker, J. The SAGE Handbook of Online Research Methods. SAGE Handb. Online Res. Methods 2012, 195-216. [CrossRef]

17. Cochran, W.G. Sampling Techniques, 2nd ed.; John Wiley \& Sons, Inc.: New York, NY, USA, 1963.

18. Yamane, T. Statistics an Introductory Analysis, 2nd ed.; Harper \& Row: New York, NY, USA, 1967.

19. Zikmund, W.G. Business Research Methods, 7th ed.; South-Western: New York, NY, USA, 2002; ISBN 0030350840.

20. Etikan, I. Comparison of Convenience Sampling and Purposive Sampling. Am. J. Theor. Appl. Stat. 2016, 5, 1-4. [CrossRef]

21. Stebbins, R.A. "Amateur" and "Hobbyist" as Concepts for the Study of Leisure Problems. Soc. Probl. 1980, 27, 413-417. [CrossRef]

22. Ferrato, J.R.; Brown, D.J.; McKinney, A. Assessment of Public Knowledge and Willingness to Pay for Recovery of an Endangered Songbird, the Golden-Cheeked Warbler. Hum. Dimens. Wildl. 2016, 21, 86-94. [CrossRef]

23. Mohamad, N.H.N. Urban residents' attitudes toward wildlife in their neighbourhoods: The case study of Klang Valley, Malaysia. Plan. Malays. 2011, 9, 19-36. [CrossRef]

24. Alejandro, L.-F. Introduction to Contingent Valuation Using Stata. 2012. Available online: https://mpra.ub.uni-muenchen.de/41 018/2/MPRA_paper_41018.pdf (accessed on 30 May 2020). 
25. Kuder, G.F.; Richardson, M.W. The Theory of the Estimation of Test Reliability. Psychometrica 1937, 2, 151-160. [CrossRef]

26. Michalski, F.; Boulhosa, R.L.P.; Nascimento, Y.N.D.; Norris, D. Rural Wage-Earners' Attitudes Towards Diverse Wildlife Groups Differ Between Tropical Ecoregions: Implications for Forest and Savanna Conservation in the Brazilian Amazon. Trop. Conserv. Sci. 2020, 13, 1940082920971747. [CrossRef]

27. Cárdenas, S.A.; Lew, D.K. Factors influencing willingness to donate to marine endangered species recovery in the Galapagos National Park, Ecuador. Front. Mar. Sci. 2016, 3, 60. [CrossRef]

28. Lundberg, P.; Vainio, A.; MacMillan, D.C.; Smith, R.J.; Veríssimo, D.; Arponen, A. The effect of knowledge, species aesthetic appeal, familiarity and conservation need on willingness to donate. Anim. Conserv. 2019, 22, 432-443. [CrossRef]

29. Colléony, A.; Clayton, S.; Couvet, D.; Saint Jalme, M.; Prévot, A.C. Human preferences for species conservation: Animal charisma trumps endangered status. Biol. Conserv. 2017, 206, 263-269. [CrossRef] 